\title{
CARACTERIZAÇÃO BIOMÉTRICA DE FRUTOS DE COQUEIRO, Cocos nucifera L. VARIEDADE ANÃ-VERDE, EM DIFERENTES ESTÁDIOS DE DESENVOLVIMENTO'
}

\author{
ANTONIO CARLOS BENASSI ${ }^{2}$, CARLOS RUGGIERO 3 , ANTONIO BALDO GERALDO MARTINS ${ }^{4}$, \\ JOSÉ ANTONIO ALBERTO DA SILVA
}

\begin{abstract}
RESUMO - Objetivou-se determinar a curva de crescimento da massa do fruto e diâmetros externos longitudinal e transversal, bem como os acúmulos do albúmen sólido (polpa) e albúmen líquido (água-de-coco) e sua caracterização sensorial em diferentes estádios. Frutos de coqueiro-anão-verde (Cocos nucifera L.) foram avaliados em 26 épocas, durante o período de sua formação, em intervalos quinzenais, de abril de 2004 a maio de 2005, no município de Bebedouro - SP. Foram aplicados aos dados modelos de regressão logística e logística combinada com exponencial quadrática, obtendo-se elevados graus de ajustes. O diâmetro externo longitudinal alcançou a média máxima de 20,12 cm aos 375 dias após a abertura da inflorescência (d.a.a.i.), enquanto o diâmetro externo transversal alcançou $14,57 \mathrm{~cm}$, aos 345 (d.a.a.i.). Os frutos apresentaram maior massa no período entre 255 e 315 (d.a.a.i.), não havendo diferença estatística significativa neste período. O albúmen sólido teve início de formação aos 225 (d.a.a.i.), chegando aos 375 dias com a massa média de 214,78 gramas. O maior volume médio de albúmen líquido foi verificado em frutos com 8,5 meses de idade com adequado sabor. Esses dados são importantes indicativos do ponto ideal de colheita dos frutos de coqueiro-anão-verde, na região de Bebedouro - SP, para o consumo in natura da água-de-coco.
\end{abstract}

Termos para indexação: características físicas, componentes do fruto, crescimento, água-de-coco, colheita.

\section{BIOMETRIC CHARACTERIZATION IN FRUITAGES OF GREEN DWARF COCONUT PALM (Cocos nucifera L.) IN DIFFERENT STAGES OF DEVELOPMENT}

\begin{abstract}
The aim of this work was to determine the growth curve of the fruit mass and the longitudinal and transversal diameter, as well as the accumulation of solid and liquid albumens (coconut water) and its sensorial characterization in different stages. Fruitages of green dwarf coconut palm (Cocos nucifera L.) were evaluated fortnightly in 26 times during the period of their formation, from April 2004 to May 2005, in the city of Bebedouro, São Paulo state. Models of logistics regression and logistics with quadratic exponential were applied to the data with the graphic collaboration of the growth curves, obtaining a high level of agreements for the evaluated parameter. The longitudinal external diameter reached 20,12 centimeters in its 375 days after the opening of the inflorescence (d.a.o.i.) and to the transversal external diameter 14,57 centimeters in its 345 (d.a.o.i.). The fruitages reached bigger mass in the period between 255 and 315 days after the opening of inflorescence, and there was no significant statistic difference in this period. The solid albumen had an initial formation in its 225 days after the opening of inflorescence, reaching the mass of 214.78 grams in its 375 days. The biggest liquid albumen volume was verified in $81 / 2$ month-old fruit, combining with the adequate taste, by sensorial evaluation of the fruitage water for its consume "in nature", pointing it as important indicatives for the ideal point of the fruitage harvest in this period in the city of Bebedouro, São Paulo state.
\end{abstract}

Index words: physical characteristics, fruitage components, growth, green coconut water, ideal point for harvest.

\section{INTRODUÇÃO}

A espécie Cocos nucifera L. apresenta número diplóide $2 \mathrm{n}=32$ cromossomos, sendo composta por algumas variedades, entre as quais, as mais importantes do ponto de vista socioeconômico e agroindustrial são a 'Typica' (var. Gigante) e 'Nana' (var. Anã) (Aragão et al., 2002b). Essa palmeira tropical é originária, provavelmente, do sudeste asiático (Fremond et al., 1975) e encontra-se disseminada por toda região intertropical, presente em mais de 86 países (Cuenca, 1998).
A variedade Anã-Verde foi inicialmente introduzida no Brasil em 1925 (Bondar, 1955; Aragão et al., 2002 b) e reproduz-se predominantemente por autofecundação, apresentando porte baixo, ciclo precoce, iniciando a produção, em média, com três anos de idade, apresentando produção entre 120 a 150 frutos/ planta/ano e com uma vida útil em torno de 35 a 40 anos. Os frutos com pouca polpa e água muito saborosa destinam-se para o consumo in natura (Leal et al., 1998).

A área cultivada, com coqueiros no mundo, em 2005, foi cerca de 10,8 milhões de hectares com uma produção de 55 milhões

\footnotetext{
${ }^{1}$ (Trabalho 126-06). Recebido em : 24-08-2006. Aceito para publicação em : 30-03-2007. Parte da Tese de Doutorado do primeiro autor apresentada à FCAV/ Unesp, Via de acesso Prof. Paulo Donato Castellane, s/n. CEP 14884-900, Jaboticabal - SP.

${ }^{2}$ Eng. Agr., MSc. Pesquisador Incaper, Rod. BR 101, Km 151, Cx P. 62, CEP 29900-970, Linhares - ES. acbenassi@incaper.es.gov.br

${ }^{3}$ Eng. Agr. Prof. Dr. Departamento de Produção Vegetal, FCAV/Unesp, Jaboticabal - SP. ruggiero@fcav.unesp.br

${ }^{4}$ Eng. Agr. Prof. Dr. Departamento de Produção Vegetal, FCAV/Unesp, Jaboticabal - SP. baldo@fcav.unesp.br

${ }^{5}$ Eng. Agr. Dr. Pesquisador Apta, Colina - SP. jaas@aptaregional.sp.gov.br
} 
de toneladas (FAO, 2006). O Brasil é o quarto maior produtor mundial, com 1,99 bilhão de frutos, em uma área colhida, em 2005, estimada em 276,8 mil hectares, sendo os cinco estados maiores produtores: Bahia, Pará, Ceará, Pernambuco e Espírito Santo (Agrianual, 2006).

No Brasil, verificou-se, na década de 1990, forte expansão do cultivo do coqueiro para regiões não-tradicionais, como foi observado no Estado de São Paulo, onde o cultivo passou de 403 ha, em 1994, para 2.542 ha, em 2005 (IBGE, 2006). Nessa região, considera-se a produção de coco uma alternativa agrícola de grande potencial por apresentar receita o ano todo, além da proximidade com os grandes centros urbanos, onde a água-decoco aumentou consideravelmente seu consumo (Tonet \& Pelinson, 1999).

Planta essencialmente tropical encontra condições favoráveis entre as latitudes $20^{\circ} \mathrm{Ne} 20^{\circ} \mathrm{S}$. Requer clima quente e úmido, sem grandes variações de temperatura, com uma média anual em torno de $27^{\circ} \mathrm{C}$, com oscilações diárias entre 5 a $7^{\circ} \mathrm{C}$. Temperaturas inferiores a $15^{\circ} \mathrm{C}$ provocam desordens fisiológicas, retardam a germinação e reduzem a porcentagem de sementes germinadas (Passos et al., 1997; Passos, 1998).

O fruto é uma drupa fibrosa. O epicarpo é uma película fina e lisa que envolve externamente o fruto, com coloração variável de verde a marrom. O mesocarpo, caracterizado por uma camada bastante grossa e fibrosa, torna-se matéria-prima com aproveitamento industrial variado, e o endocarpo, lenhoso, duríssimo, de coloração escura é utilizado com fins industrial e artesanal.

Na parte interna, encontram-se o albúmen sólido, a polpa branca, oleosa, com espessura variável e que inicia sua formação na região polar oposta ao embrião, que se estende posteriormente por toda a cavidade interna (Medina, 1980). Segundo Aragão et al. (2002a), seu início de formação ocorre nos frutos com idade entre 150 e 180 dias.

Entre o endocarpo e o endosperma, existe uma fina camada de coloração marrom (tegumento), aderida fortemente ao albúmen sólido (polpa).

O coco adquire tamanho e peso máximos quando tem cerca de seis meses de idade, com o peso e o tamanho mantendo-se constantes durante um ou dois meses, quando o peso decresce muito, e o tamanho, ligeiramente. A perda de água justifica esse decréscimo (Gomes, 1984).

Na região central da noz, aparece uma grande cavidade, parcialmente preenchida com albúmen líquido (água-de-coco) (Child, 1974). A água-de-coco começa a se formar a partir do segundo mês após a abertura da inflorescência e alcança seu volume máximo entre 6 e 7 meses de idade, período este recomendado para a sua colheita (Resende et al., 2002). Segundo Fontes et al. (1998), quando a produção se destina ao consumo da água-de-coco, o fruto deve ser colhido entre 6 e 8 meses de idade.

De acordo com Aragão et al. (2001), nos frutos com idade entre 6 e 7 meses, a água-de-coco corresponde a aproximadamente
$25 \%$ do peso do fruto.

O objetivo deste trabalho foi determinar a curva de crescimento do fruto do coqueiro anão-verde, avaliando-se os diâmetros longitudinal e transversal, as massas do fruto, albúmen sólido, albúmen líquido e a massa da casca, fibras, endocarpo e brácteas e estabelecer a curva de acúmulo da água-de-coco no interior da noz, além de sua avaliação sensorial nos diferentes estádios de formação.

\section{MATERIAL E MÉTODOS}

O trabalho de campo foi realizado em um coqueiral (Cocos nucifera L.), variedade Anã-Verde, na Estação Experimental de Citricultura de Bebedouro, município de Bebedouro - SP, a $20^{\circ} 53^{\prime} 16^{\prime \prime}$ de Latitude sul, $48^{\circ} 28^{\prime} 11^{\prime \prime}$ Longitude oeste e altitude de 601 metros, em solo classificado como Latossolo Vermelho-Escuro.

O clima, segundo classificação de Köpeen, é do tipo Cwa, com inverno moderado e seco e verão quente e chuvoso. Durante o período de execução do experimento, abril de 2004 e maio de 2005 , a temperatura média geral foi de $22,2^{\circ} \mathrm{C}$, com temperatura média das mínimas de $12,6^{\circ} \mathrm{C}$ registrada no mês de julho, e média das máximas de $33,6^{\circ} \mathrm{C}$ em setembro. Neste período, 14 meses, a precipitação pluvial totalizou $1.586,1 \mathrm{~mm}$, com período de seca entre os meses de junho e setembro, com ocorrência mínima de $0,2 \mathrm{~mm}$ registrada em agosto (Figura 1 ).

O coqueiral foi plantado em janeiro de 1997, com mudas procedentes da Empresa de Pesquisa Agropecuária do Rio Grande do Norte (EMPARN), no espaçamento de 7,0 m entre linhas e 6,0 $\mathrm{m}$ entre plantas, em disposição triangular. As plantas dispunham de sistema de irrigação, com dois microaspersores por planta. $\mathrm{O}$ controle das plantas invasoras foi realizado mecanicamente com a roçadeira nas entrelinhas e nas linhas, e na coroa das plantas, com o herbicida glifosate. $\mathrm{O}$ tratamento fitossanitário adotado foi basicamente utilizando-se de produtos para o controle de ácaros e lagartas.

Em um intervalo de cinco dias, cem inflorescências, uma por planta, foram marcadas no momento de sua abertura. A partir das inflorescências marcadas, foram realizadas 26 épocas de colheita, com intervalo quinzenal, sendo a primeira no dia da abertura da inflorescência e a última aos 375 dias. Para cada época, foram colhidos 25 frutos, retirados de oito plantas, sendo em média três frutos por cacho marcado. Cada fruto foi considerado como sendo uma repetição.

Os frutos foram transportados ao laboratório do Departamento de Produção Vegetal da UNESP-FCAV, Jaboticabal - SP, e após a lavagem com detergente neutro sob água corrente, foram numerados e colocados sobre a bancada para a determinação de suas características físicas.

O diâmetro externo longitudinal (DEL) e o diâmetro externo transversal (DET) foram determinados com o auxílio de um paquímetro digital, sendo que, a partir da avaliação aos 135 dias de idade, devido ao tamanho, os frutos foram avaliados com uma suta, sendo os valores expressos em $\mathrm{cm}$. 
A massa dos frutos (MF) foi determinada em balança digital com precisão de 0,01 gramas. Após pesagem, os frutos foram perfurados e o albúmen líquido (água-de-coco) foi coletado e mensurado (MAL). Posteriormente, os frutos foram abertos ao meio, separando-se e determinando-se a massa do albúmen sólido (MAS). Por diferença do valor da massa total do fruto, menos as massas dos albumens líquido e sólido, calculou-se a massa do epicarpo + mesocarpo + endocarpo + brácteas (MEMEB), sendo o resultado expresso em gramas.

Para a determinação do sabor da água-de-coco, foi efetuada avaliação sensorial (AS) em amostras do albúmen líquido oferecidas a dez provadores não-treinados. Para cada época avaliada, ofereceu-se cerca de $100 \mathrm{~mL}$ da água-de-coco, para cada provador, que emitiu uma nota através de uma escala de 1 a 10, correspondendo os maiores valores, ao melhor sabor.

As médias foram comparadas através do teste de Tukey, ao nível de 5\% de probabilidade. Para a confecção das figuras, os dados analisados referentes à DEL e MAS foram ajustados, utilizando-se de uma função de regressão logística, $\mathrm{Y}=\mathrm{A} /[1+\mathrm{e}$ $-\mathrm{k}(\mathrm{x}-\mathrm{xc})]$ sendo: $\mathrm{Y}=$ valor médio da característica avaliada; $\mathrm{A}=$ máximo assintótico (crescimento máximo); e = base do logaritmo neperiano; $\mathrm{k}=$ taxa média de crescimento; $\mathrm{x}=$ tempo (em dias após a abertura da inflorescência), e xc = tempo em que a variável Y atinge metade do crescimento máximo.

Para os dados relativos à DET, MF, MAL e MEMEB, ajustou-se uma função obtida pela composição de uma função logística com uma exponencial quadrática, dada por: $\mathrm{Y}=\mathrm{A} /[1+$ $\left.e^{-k(x-x c)}\right]+\left[e^{\left(a+b x+c x^{2}\right)}\right]$.

\section{RESULTADOS E DISCUSSÃO}

Os valores referentes às variáveis das funções utilizadas para estimar o diâmetro esterno longitudinal (DEL), diâmetro externo transversal (DET), massa do fruto (MF), massa do epicarpo + mesocarpo + endocarpo + brácteas (MEMEB), massa do albúmen líquido (MAL) e massa do albúmen sólido estão apresentados na Tabela 1 .

O diâmetro externo longitudinal (DEL) dos frutos de coqueiro-anão-verde variou de $1,98 \mathrm{~cm}$, no primeiro dia da abertura da inflorescência (d.a.a.i.), até 20,12 cm registrado aos 375 (d.a.a.i.). Este valor foi maior que aquele obtido por Magalhães (1999), de $18,2 \mathrm{~cm}$, e próximo àquele obtido por Aragão et al. (2002a), de $22,69 \mathrm{~cm}$, ambos obtidos em frutos com oito meses de idade.

O maior incremento no crescimento do fruto foi observado no período entre 60 e 255 d.a.a.i. Verificou-se não haver diferença estatística nos resultados entre 300 e 375 d.a.a.i., os quais variaram, respectivamente, de 19,60 e 20,12 cm (Figura 1). Os dados obtiveram um alto grau de ajuste através de uma função logística, sendo os valores da equação apresentados na Tabela 1 .

O diâmetro externo transversal (DET) do fruto variou de $2,18 \mathrm{~cm}$, na abertura da inflorescência, até $14,57 \mathrm{~cm}$, aos 345 d.a.a.i., com o maior incremento no crescimento, no período entre 75 e
255 d.a.a.i. Entretanto, não houve diferença significativa para os valores encontrados entre os 315 e 375 d.a.a.i., os quais variaram, respectivamente, de 14,44 a 14,21 cm (Figura 2). Os dados obtidos estão de acordo com aqueles observados por Magalhães (1999), que obteve valor de $14,5 \mathrm{~cm}$, porém inferior àquele obtido por Aragão et al. (2002a), que encontraram valor de 17,2 cm.

$\mathrm{O}$ valor médio encontrado para a massa do fruto (MF) variou de 5,33 gramas, na abertura da inflorescência, até 1.671,71 gramas, aos 315 d.a.a.i. (Figura 3). Frutos com maiores massas foram encontrados no período entre 9 e 9,5 meses, discordando de Aragão et al. (2001), que encontraram, entre 6 e 7 meses, o máximo desenvolvimento e peso em frutos de coqueiro-anãoverde cultivados em Sergipe.

A curva revelou acentuado ganho de massa no período entre 150 e 270 d.a.a.i, porém, entre 255 e 315 d.a.a.i., não houve diferença significativa para os valores encontrados, registrandose, respectivamente, $1.566,94 \mathrm{~g}$ e 1.671,72 gramas.

Após 315 dias, verificou-se constante redução na massa dos frutos, apresentando, aos 375 dias, 1.243,19 gramas. A função utilizada para estimar a massa do fruto, com seus respectivos valores, encontra-se na Tabela 1 .

O crescimento no tamanho e na massa dos frutos foi relativamente menor na fase inicial de sua formação, entre os meses de abril e julho, provavelmente, pelas baixas temperaturas verificadas nesse período, onde se registraram, entre os meses de maio e agosto, temperaturas mínimas inferiores a $15^{\circ} \mathrm{C}$ (Figura 1). Estas observações são reforçadas por Fremond et al. (1975), os quais afirmam que temperaturas inferiores a $15^{\circ} \mathrm{C}$ provocam desordens fisiológicas, como parada do crescimento e abortamento de flores. Segundo Passos et al. (1997), na região noroeste de São Paulo, temperaturas mais baixas nos meses de junho a agosto interferiram na fisiologia da planta jovem, retardando a germinação e reduzindo a porcentagem de sementes germinadas.

Os valores médios para a massa do epicarpo + mesocarpo + endocarpo + brácteas (MEMEB) variaram de 5,33 gramas, na abertura da inflorescência, a 1.285,60 gramas, aos 315 d.a.a.i. Este valor não diferiu significativamente dos valores obtidos no período entre 255 e 315 d.a.a.i. Após 285 d.a.a.i., verificou-se constante redução na massa do parâmetro avaliado, sendo registrado 853,36 gramas aos 375 d.a.a.i. (Figura 3).

O albúmen sólido apresenta-se, inicialmente, como uma fina camada líquido-gelatinosa, sendo depositada na região polar oposta ao embrião, que se estende, posteriormente, por toda a cavidade interna e adquire consistência sólida, conforme também observado por Medina (1980). O início de formação do albúmen sólido, aos 210 d.a.a.i., difere da indicação de Aragão et al. (2002a), que relatam seu início de formação em frutos entre 150 e 180 dias de idade.

Aos 225 d.a.a.i., o valor encontrado para a massa do albúmen sólido (MAS) foi de 3,47 gramas, com formação crescente, em todas as épocas avaliadas, e alcançou, aos 375 dias, a massa de 214,78 gramas (Figura 3). Nesta época, em relação à massa 
total do fruto, a água-de-coco representou 14,08\%, o albúmen sólido $17,28 \%$ e a casca + fibra + endocarpo + brácteas a $68,64 \%$.

A abertura da cavidade no interior do fruto teve início aos 45 d.a.a.i., sendo observado o início da formação do albúmen líquido aos 75 d.a.a.i., divergindo dos resultados obtidos por Aragão et al. (2002a), que indicaram o início da formação da águade-coco aos 60 dias.

Aos 255 dias de idade, 8,5 meses após a abertura da inflorescência, foi encontrado o maior valor médio para a massa do albúmen líquido de 292,39 gramas, com variação de 242,66 gramas a 353,42 gramas.

Nos frutos com idade de 8,5 meses, a massa média do fruto foi de 1.566,94 gramas, albúmen líquido 292,39 gramas, albúmen sólido 51,96 gramas e para casca + fibra + endocarpo + brácteas, 1.222,59 gramas. Assim, em relação à massa total do fruto, a água-de-coco representou 18,66\%, o albúmen sólido 3,32\% e a casca, fibra, endocarpo e brácteas $78,02 \%$. O valor de $18,66 \%$ encontrado para a água-de-coco, em relação ao peso total do fruto, foi menor que aquele de $25 \%$ observado por Aragão et al. (2001).

A partir de 8,5 meses após a abertura da inflorescência, a quantidade de água-de-coco sofreu contínua redução, chegando aos 12,5 meses com média de 175,04 gramas, ou seja, redução de $40,17 \%$. Assim, considerando-se um período de 4 meses entre estas avaliações, e admitindo-se uma queda constante, verificouse redução no albúmen líquido, média mensal, de 10,04\%.

A metodologia utilizada para quantificar o albúmen líquido foi através da determinação de sua massa. Embora os valores de sua densidade tenham variado de 1,0030 a $1,0204 \mathrm{~g} / \mathrm{mL}$, relativos às avaliações aos 6 e 11 meses, respectivamente, para efeito de comparações com dados na literatura, admitiu-se densidade igual a 1,00, convertendo-se gramas do albúmen líquido em $\mathrm{mL}$. Desta forma, o valor médio obtido de $292,4 \mathrm{~mL}$ foi superior àquele citado por Magalhães (1999), que observou média de $177 \mathrm{~mL}$ de água- de-coco em frutos de coco-anão-verde, aos oito meses de idade e semelhantes àquele obtido por Campos et al. (1996), que encontraram média de $297 \mathrm{~mL}$ de água-de-coco, em frutos de cocos verdes disponíveis no mercado.

Os valores atribuídos para o sabor da água-de-coco puderam ser estabelecidos, quinzenalmente, nos frutos entre $5 \mathrm{e}$ 12,5 meses de idade. A menor nota média foi de 1,4 atribuída para a água-de-coco em frutos com 150 dias de idade, e o valor máximo de 9,6 para frutos com idade de 285 dias. Considerando-se, como aceitável, o sabor da água-de-coco com notas igual ou superior a 7,0 , verificou-se que estes índices foram obtidos em frutos com idade entre 8 e 11 meses (Figura 4).

A relação entre o volume e o sabor da água-de-coco, expressa na Figura 4, revelou que, entre 8 e 10,5 meses, o conteúdo médio, por fruto, foi próximo ou superior a $250 \mathrm{~mL}$, e as notas para o sabor variaram de 7,3 e 9,6, indicando um período propício para a colheita dos frutos.

Assim, considerando-se o volume e o sabor da água-decoco no fruto, recomenda-se a colheita aos 8,5 meses de idade. Entretanto, segundo Benassi (2006), para a região de Bebedouro - SP, colheitas de frutos com idade inferior a 8 meses seriam desaconselháveis pelo menor conteúdo de água-de-coco e principalmente pelo sabor menos agradável.

Estes resultados discordam de Fremond et al. (1975), Resende et al. (2002), Aragão et al. (2001) e Aragão et al. (2002a), que recomendam, para a região Nordeste, a colheita de frutos do coqueiro-anão, para o consumo da água-de-coco, entre 6 e 7 meses, e parcialmente de Fontes et al. (1988), que recomendam colheita entre 6 e 8 meses de idade. Provavelmente, o clima local, especialmente as temperaturas amenas registradas no período de formação dos frutos, interferiram no crescimento e no desenvolvimento, alterando, inclusive, a época ideal preconizada, na região Nordeste brasileira, para a colheita dos frutos do coqueiro-anão para o consumo in natura da água-de-coco.

TABELA 1 - Valores determinados para as variáveis das funções relativas ao diâmetro externo longitudinal (DEL), diâmetro externo transversal (DET), massa do fruto (MF), massa do epicarpo + mesocarpo + endocarpo + brácteas (MEMEB), massa do albúmen líquido (MAL) e massa do albúmen sólido (MAS), em frutos de coqueiro-anão-verde, em Bebedouro - SP, no período de abril de 2004 a maio de 2005.

\begin{tabular}{|c|c|c|c|c|c|c|c|c|}
\hline \multirow{2}{*}{$\begin{array}{l}\text { Caract. } \\
\text { biométr. }\end{array}$} & \multirow{2}{*}{$\begin{array}{c}\text { Função } \\
\text { tipo }\end{array}$} & \multicolumn{6}{|c|}{ Valores das variáveis das funções } & \multirow{2}{*}{$\mathrm{R}^{2}$} \\
\hline & & A & $\mathrm{k}$ & $\mathrm{xc}$ & $\mathrm{a}$ & $\mathrm{b}$ & $\mathrm{c}$ & \\
\hline 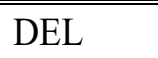 & 1 & 21,56296 & 0,01462 & 165,14631 & - & - & - & 0,995 \\
\hline DET & 2 & 88,55323 & 0,005 & 722,67494 & $-6,3575$ & 0,06183 & $-0,0001175$ & 0,997 \\
\hline MF & 2 & 1251,0995 & 0,01641 & 291,2917 & $-7,2516$ & 0,10101 & $-0,000179$ & 0,994 \\
\hline MEMEB & 2 & 789,53267 & 0,01999 & 227,51147 & $-13,20784$ & 0,13879 & $-0,000244$ & 0,997 \\
\hline MAL & 2 & 162,22997 & 0,10815 & 302,56306 & $-9,71007$ & 0,1199 & $-0,0002347$ & 0,995 \\
\hline MAS & 1 & 230,47004 & 0,03131 & 299,99169 & - & - & - & 0,986 \\
\hline
\end{tabular}

Função tipo $1=\mathrm{Y}=\mathrm{A} / 1+\mathrm{e}^{-\mathrm{k}(\mathrm{x}-\mathrm{xc})}$

Função tipo $2=\mathrm{Y}=\mathrm{A} /\left[1+\mathrm{e}^{-\mathrm{k}(\mathrm{x}-\mathrm{xc})}\right]+\left[\mathrm{e}^{\left(\mathrm{a}+\mathrm{bx}+\mathrm{cx}{ }^{2}\right)}\right]$ 


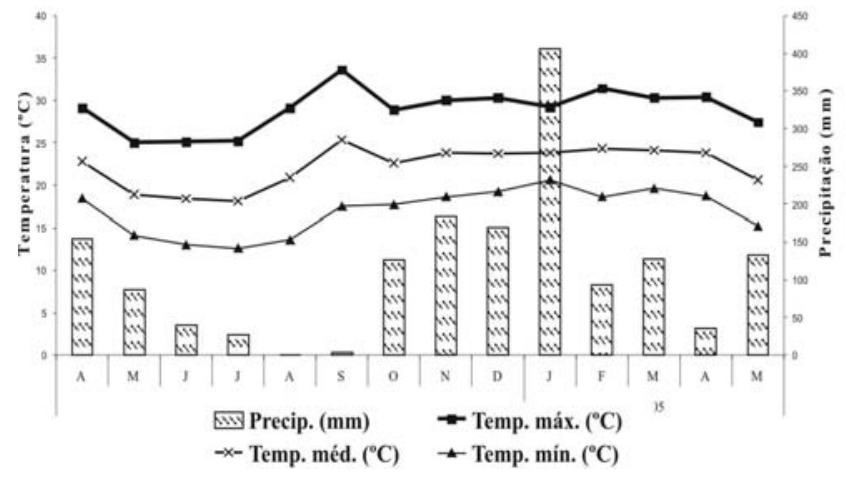

FIGURA 1 - Médias mensais de temperaturas $\left({ }^{\circ} \mathrm{C}\right)$ e precipitação pluvial (mm) na EECB, Bebedouro - SP, no período de abril de 2004 a maio de 2005.

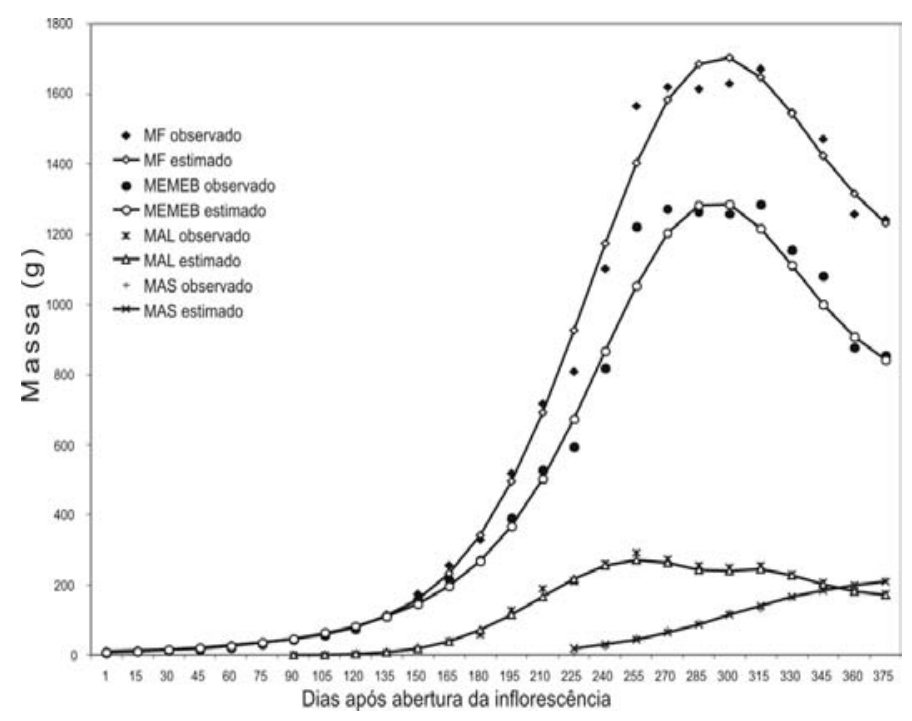

FIGURA 3 - Valores observados e estimados para a massa do fruto (MF), massa do epicarpo + mesocarpo+ endocarpo+ brácteas (MEMEB), massa do albúmen líquido (MAL) e massa do albúmen sólido (MAS), em frutos de coqueiro-anão-verde, coletados em diferentes estádios de formação, no período de abril de 2004 a maio de 2005, em Bebedouro - SP.

\section{CONCLUSÕES}

Nas condições ambientais em que foi desenvolvido o trabalho, pode-se concluir:

1- Para o diâmetro externo longitudinal e massa do albúmen sólido, a função logística foi a que melhor se ajustou ao modelo de crescimento, enquanto, para diâmetro externo transversal, massa do fruto, massa do albúmen líquido e massa do epicarpo + mesocarpo + endocarpo + brácteas, ajustaram-se

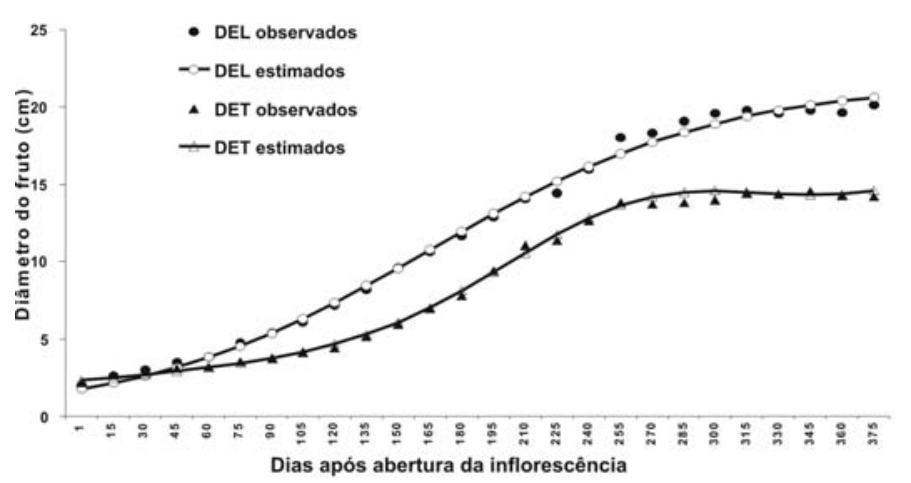

FIGURA 2 - Valores observados e estimados para o diâmetro externo longitudinal (DEL) e diâmetro externo transversal (DET), em frutos de coqueiro-anãoverde, coletados em diferentes estádios de formação, no período de abril de 2004 a maio de 2005, em Bebedouro - SP.

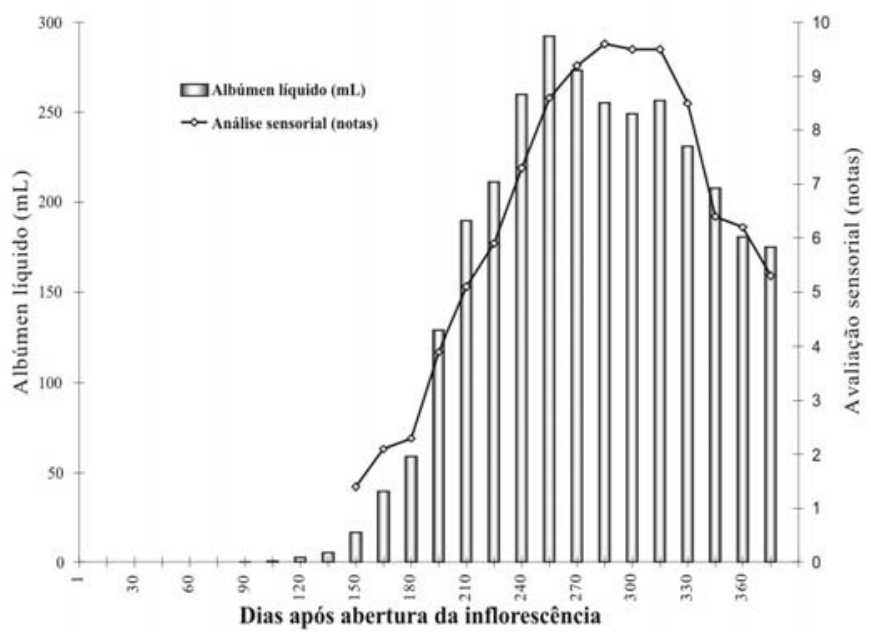

FIGURA4 - Volume do albúmen líquido $(\mathrm{mL})$ e avaliação sensorial (notas) em frutos de coqueiro-anão-verde em diferentes estádios de formação, no período de abril de 2004 a maio de 2005, em Bebedouro - SP.

melhor através de uma função logística combinada com uma exponencial quadrática.

2- O maior volume médio para albúmen líquido (água-decoco) com adequado sabor foi obtido em frutos com 8,5 meses de idade, sendo considerada a melhor época para a colheita de frutos para o consumo in natura da água-de-coco.

3- Aos 8,5 meses, em relação à massa total do fruto, a água-de-coco correspondeu a 18,66\%, albúmen sólido 3,32\% e casca + fibra + endocarpo + brácteas a 78,02\%. 


\section{AGRADECIMENTOS}

À Estação Experimental de Citricultura de Bebedouro, pela gentileza em ceder a área para a realização do trabalho de campo.

Ao Dr. José Carlos Barbosa, Professor Titular do Departamento de Ciências Exatas da Faculdade de Ciências Agrárias e Veterinárias - UNESP - FCAV, Câmpus de Jaboticabal, pelos ajustes matemáticos e orientação na análise estatística dos dados.

\section{REFERÊNCIAS}

AGRIANUAL 2006: anuário da agricultura brasileira. Coco-dabaía. São Paulo: FNP, Consultoria e Agroinformativos, 2006. p. 286-292.

ARAGÃO, W.M.; CRUZ, E.M.O.; HELVÉCIO, J. S. Caracterização morfológica do fruto e química da água de coco em cultivares de coqueiro-anão. Agrotrópica, Ilhéus, v. 13, n. 2, 2001. p. 4958.

ARAGÃO, W.M.; RESENDE, J.M.; CRUZ, E.M.O.; REIS, C.S.; SAGGIN JUNIOR, O.J.; ALENCAR, J.A. de; MAREIRA, W.A.; PAULA, F.R. de; LIMA FILHO, J.M.P. Fruto do coqueiro para consumo natural. In: ARAGÃO, W.M. (Ed.). Coco pós-colheita. Brasília: EMBRAPA, 2002a. p.19-25. (Série Frutas do Brasil, 29).

ARAGÃO, W.M.; RIBEIRO, F.E.; TUPINAMBÁ, E.A.; SIQUEIRA, E.R. de. Variedades e híbridos do coqueiro. In: ARAGÃO, W.M. (Ed.). Coco pós-colheita. Brasília: EMBRAPA, Informe Tecnológico, 2002 b. p. 26-34. (Série Frutas do Brasil, 29).

BENASSI, A.C. Caracterizações biométrica, química e sensorial de frutos de coqueiro variedade Anã Verde. 2006. 98 f. Tese (Doutorado em Produção Vegetal) - Faculdade de Ciências Agrárias e Veterinárias, Universidade Estadual Paulista, Jaboticabal, 2006.

BONDAR, G. A cultura do coqueiro (Cocos nucifera) no Brasil. Salvador: Tipografia Naval, $1955.91 \mathrm{p}$.

CAMPOS, C. F.; SOUZA, P. E. A.; COELHO, J. V.; GLÓRIA, M. B. A. Chemical composition, enzyme activity and effect of enzyme inactivation on flavor quality of green coconut water. Journal of Food Processing and Preservation, Atlanta, v. 20, p. 487-500, 1996.

CHILD, R. Coconuts. $2^{\text {nd }}$ ed. London: Longman, 1974. 335 p.

CUENCA, M. A. G. Importância econômica do coqueiro. In: FERREIRA, J. M. S.; WARWICK, D. R. N.; SIQUEIRA, L. A. (Ed.). A cultura do coqueiro no Brasil. 2. ed. Aracaju: EmbrapaSPI, 1998. p. 17-56.

FAO 2006. Disponível em: <http://www.faostat.org.br>. Acesso em: 10 mar. 2006.

FONTES, H. R.; CINTRA, F. L. D.; CARVALHO FILHO, O. M de. Implantação e manejo da cultura do coqueiro. In: FERREIRA, J. M. S.; WARWICK, D. R. N.; SIQUEIRA, L. A. (Ed.). A Cultura do coqueiro no Brasil. 2. ed. Aracaju: Embrapa-SPI, 1998.p. 99-128.

FREMOND, Y.; ZILLER, R.; NUCE de LAMOTHE, M. de. El cocotero: técnicas agrícolas y producciones tropicales. Barcelona: Editorial Blume, 1975.236 p.
GOMES, P. O coqueiro-da-baía. 7. ed. São Paulo: Nobel, 1984. 111 p.

IBGE. Instituto Brasileiro de Geografia e Estatística. Disponível em: $<$ http://www.ibge.gov.br $>$. Acesso em: 10 mar. 2006.

LEAL, E.C.; PASSOS, E.E.M.; RIBEIRO, F.E.; FONTES, H.R.; FERREIRA, J.M.S.; SOBRAL, L.F.; NOGUEIRA, L.C.; CUENCA, M.A.G.; ARAGÃO, W.M. Recomendações técnicas para o cultivo do coqueiro. In: CURSO sobre a cultura do coqueiro, 5., 1998, Aracaju: Embrapa, 1998. p.3-26.

MAGALHÃES, J.A.S. de. Características físicas e químicas da água e do albúmen de cultivares de coco (Cocos nucifera $\mathrm{L}$.) provenientes da Estação Experimental da PESAGRO RJ/ Campos. 1999. 60 f. Dissertação (Mestrado em Produção Vegetal) - Centro de Ciências e Tecnologias Agropecuárias, Universidade Estadual do Norte Fluminense, Campos dos Goytacazes, 1999.

MEDINA, J.C. Coco I-Cultura. In: Medina et al. (Ed.). Coco da cultura ao processamento e comercialização. São Paulo: ITAL, 1980. 285 p. (Série Frutas Tropicais, 5)

PASSOS, E.E.M.; CONCEIÇÃO, M.A.F.; MAIA, J.D.G. Germinação da semente e desenvolvimento da plântula de coqueiro no Noroeste de São Paulo. Aracaju: EmbrapaCPATC, 1997. 5 p. (Comunicado Técnico, 12)

PASSOS, E.E.M. Ecofisiologia do coqueiro. In: FERREIRA, J.M S.; WARWICK, D.R.N.; SIQUEIRA, L.A. (Eds.). A cultura do coqueiro no Brasil. 2. ed. Aracaju: Embrapa-SPI, 1998. p. $65-$ 72.

RESENDE, J.M.; ASSIS, J.S. de.; REIS, C.S.; ARAGÃO, W.M. Colheita e manuseio pós-colheita. In: ARAGÃO, W. M. (Ed.). Coco pós-colheita. Brasília: EMBRAPA, 2002.p.35-41. (Série Frutas do Brasil, 29).

TONET, R.M.; PELINSON, G.J.B. A situação da cultura do coqueiro no Estado de São Paulo. In: SÃO JOSÉ, A.R.; SOUZA, I.V.B.; MOURA, J.I.L.; REBOUÇAS, T.N.H. Coco produção e mercado. Vitória da Conquista: DFZ/UESB, 1999. p.222-238. 